J. Lake Sci.(湖泊科学), 2009, 21(6): 806-812

http://www.jlakes.org. E-mail: jlakes@niglas.ac.cn

(C)2009 by Journal of Lake Sciences

\title{
滇池北部湖湾不同底泥性状对微囊藻复苏影响的模拟*
}

\author{
万 能 ${ }^{1,2}$, 汤 俊 ${ }^{1,2}$, 李 林 $^{1}$, 郑凌凌 ${ }^{1}$, 宋立荣 $1^{* *}$ \\ (1: 中国科学院水生生物研究所淡水生态及生物技术国家重点实验室, 武汉 430072) \\ (2: 常熟理工学院生物与食品工程学院, 常熟 215500)
}

摘 要: 滇池北部福保湾主要承接上游昆明市的生活污水及周边工业污水, 其污染程度极为严重. 本研究在福保湖湾内设置 4 个采样点, 分别采集了不同区域的沉积物, 首次模拟研究了微囊藻(Microcystis)在不同沉积物环境中复苏能力差异, 结果表 明微囊藻在模拟实验中的复苏能力表现出对不同底质的不同适应性，人口湖区的沉积物对微囊藻的复苏有极强的抑制作用. 藻类复苏后达到的最大生物量(以叶绿素 a 计)分别为东岸对照区的 4.7\%, 西岸对照区的 6.6\%及吹填区的 $11.9 \%$, 其中微囊藻 生物量也远低于其它各样点，占东岸对照、吹填区及西岸对照的比例分别为 $5.2 \% 、 10.3 \%$ 和 $19.4 \%$. 以上研究暗示了河口处沉 积物不适合微囊藻的复苏. 福保湾藻类水华的种源贡献应该主要依靠外源性输人, 即湖流场和风向所导致的藻类水平迁移贡 献远远大于底泥复苏至水体的垂直迁移，

关键词: 福保湾; 滇池; 沉积物; 微囊藻; 复苏率; 模拟研究; 外源性输人

\section{Simulation on the sediments affecting Microcystis recruitment in north bay of Lake Dianchi}

\author{
WAN Neng ${ }^{1,2}$, TANG Jun ${ }^{1,2}$, LI Lin ${ }^{1}$, ZHENG Lingling ${ }^{1} \&$ SONG Lirong ${ }^{1}$ \\ (1: State Key Laboratory of Freshwater Ecology and Biotechnology, Institute of Hydrobiology, Chinese Academy of Sciences, Wuhan \\ 430072, P.R.China) \\ (2: School of Biology and Food Engineering, Changshu Institute of Technology, Changshu 215500, P.R.China)
}

\begin{abstract}
Fubao Bay is located in the north of Lake Dianchi, which is one of the most seriously polluted bays in the lake. Two main rivers, Haihe River and Daqinghe River flow into Fubao Bay from the north. Four sampling sites were settled in this bay, and the sediment samples were collected by using Petersen grab. For the first time, the study of recruitment ability of Microcystis in different sediment environments was carried out in simulation devices. The results in the present study showed that the recruitment ability of Microcystis was quite different depended on its habitat environments. The Microcystis recovery was inhibited in lacustrine sediments near estuary, and the maximum biomass (calculated as chlorophyll-a) was pretty lower than other sampling sites. Compared among East Coast Area, West Coast Area and Hydraulic Mud Fill Area, the Microcystis biomass were only 4.7\%, 6.6\% and 11.9\%, respectively. And Microcystis biomass (calculated as Microcystis cell numbers) were about 5.2\%, 10.3\% and 19.4\%, corresponding. All the results indicated that sediments in estuary of Fubao Bay were not appropriate for Microcystis recruitment. The contribution of “seeds bank” recruiting to form HABs in this bay could be much less than the wind-induced external loading. All these results could be helpful in Microcystis blooms forecasting, preventing and controlling in the future.
\end{abstract}

Keywords: Fubao Bay; Lake Dianchi; sediment; Microcystis; recruitment rate; simulation study; external loading

自 20 世纪 80 年代以来, 滇池水体富营养化程度迅速加深, 蓝藻水华频发, 且暴发强度大, 时间跨度

* 国家重点基础研究发展计划项目(2008CB418006)、NSFC-云南联合基金项目(U0833604)和国家水体污染控制与治理科 技重大专项项目(2008ZX07102-005)联合资助. 2009-02-16 收稿; 2009-07-06 收修改稿. 万能, 男, 1978 年生, 博士, 讲 师; E-mail: hbwallon@hotmail.com.

** 通讯作者; E-mail: lrsong@ihb.ac.cn. 
长, 在世界范围内也属罕见, 其水华优势种一年中大部分时间主要为铜绿微囊藻(Microcystis aeruginosa), 而在早春季节则是水华束丝藻(Aphanizomenon flos-aqaue $)^{[1]}$. M. aeruginosa 在湖泊底泥附近越冬并在翌年 初春季节复苏并最终暴发水华 ${ }^{[2-4]}$. 一般认为湖泊水华的初期暴发并不是全湖性质的全面暴发, 应是由点 到面的逐渐扩散的过程. 国内有学者认为太湖南部水华的暴发早于北部湖湾, 然后随着湖流场及风向的 变化逐渐迁移至北部梅梁湾、贡湖湾, 并在此大规模暴发. 我们在滇池的研究也发现, 北部湖湾与南部湖 湾水华暴发的时间不完全一致，由此我们推测由于不同湖区的不同特点导致微囊樥复苏时间存在差异， 即微囊藻复苏的能力存在时空差异性 ${ }^{[1]}$.

对微囊藻复苏的研究目前有一些共识, 即合适的温度、光照对其复苏具有重要启动效应, 而溶解氧 和营养盐也能影响其复苏过程 ${ }^{[5-11]}$; 此外, 物理或生物扰动也能对其复苏产生影响 ${ }^{[12-16]}$. Yin 等通过对 PCC6803 的研究发现, 该藻株对低温光照条件敏感, 不利于藻株存活 ${ }^{[17]}$; Yang 等进一步研究发现藻株内 $\alpha$-维生素 E 含量增加对其存活率提升有较大影响 ${ }^{[18]}$; 而 Wan 等的最新研究结果揭示了微囊澡在为期 $31 \mathrm{~d}$ 的底泥环境中, 显示出了一定的抗逆性, 且 PS II 活性能较快恢复 ${ }^{[19]}$.

滇池属于浅水湖泊, 没有温跃层, 温度差异较小, 所以微囊藻的复苏应不存在温度限制作用; 且滇 池北部湖湾透明度水平较低, 底泥附近接受的光强很低, 某些区域甚至为零(如北部福保湾河口区), 其光 强抑制效应差异极小. 但以前的研究结果已发现滇池的微囊藻细胞在不同的时空分布格局中显示出了不 同的生理生态差异性，这种差异性暗示了滇池的微囊藻复苏效率可能还受到其它方面的影响，例如在不 同性状的底泥环境中, 其复苏能力可能存在差异性, 但这方面的研究前人并未涉及. 本研究以揭示不同 区域沉积物差异性对微囊藻复苏能力为出发点, 希望能从全新的角度发现滇池不同区域、不同性状的沉 积物对微囊藻复苏能力的影响, 并给蓝藻水华的预防及控制提供新的思路.

\section{1 材料与方法}

\section{1 研究材料与模拟装置}

滇池北部福保湾是滇池外海污染较重的区域, “受纳湖湾污染负荷有效消减和生态系统重建技术研究 与工程示范”(国家自然科学基金项目及 “863”课题)在此开展了一系列诸如湖湾底质改造及吹填的生态重 建工程. 本研究用彼得森采泥器采集了北部福保湾不同区域的底泥用于模拟研究, 设置了东岸对照区、 吹填区、河口区及西岸对照区 4 个组, 分别对应图 1 中 $1^{\#} 、 2^{\#} 、 3^{\#}$ 和 $4^{\#}$. 底泥采集后, 分别置于玻璃模拟 装置中 $(30 \mathrm{~cm} \times 30 \mathrm{~cm} \times 80 \mathrm{~cm})$ (图 2), 同时测定沉积物性状指标. 然后注人新采集的富藻湖水 (M. aeruginosa 优势度超过 99\%), 遮光诱导 M. aeruginosa 沉降. 在遮光诱导时, 整个装置完全用黑布包裹, 遮光 $12 \mathrm{~d}$ 后,
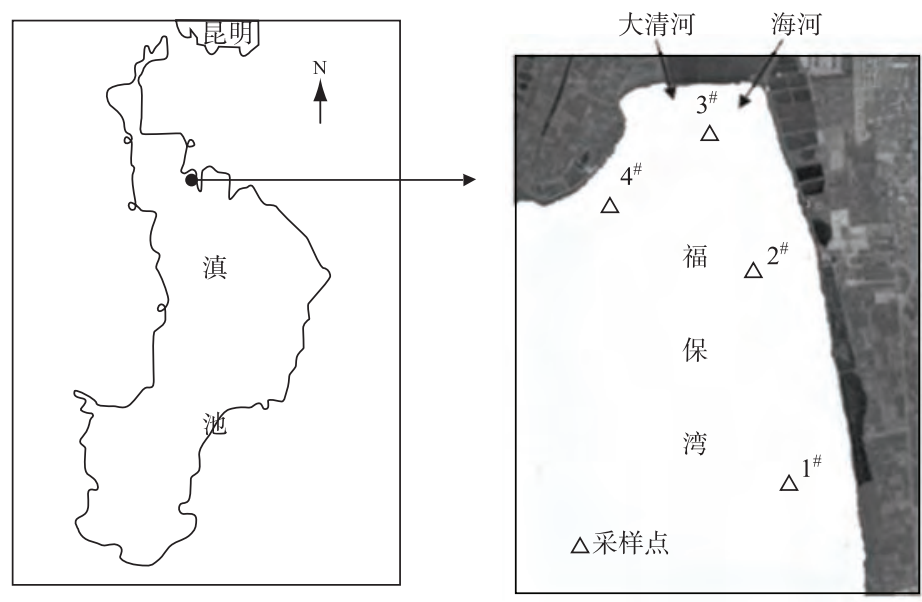

图 1 滇池福保湾及采样位点分布

Fig.1 Locations of Fubao Bay and sampling sites in Lake Dianchi 

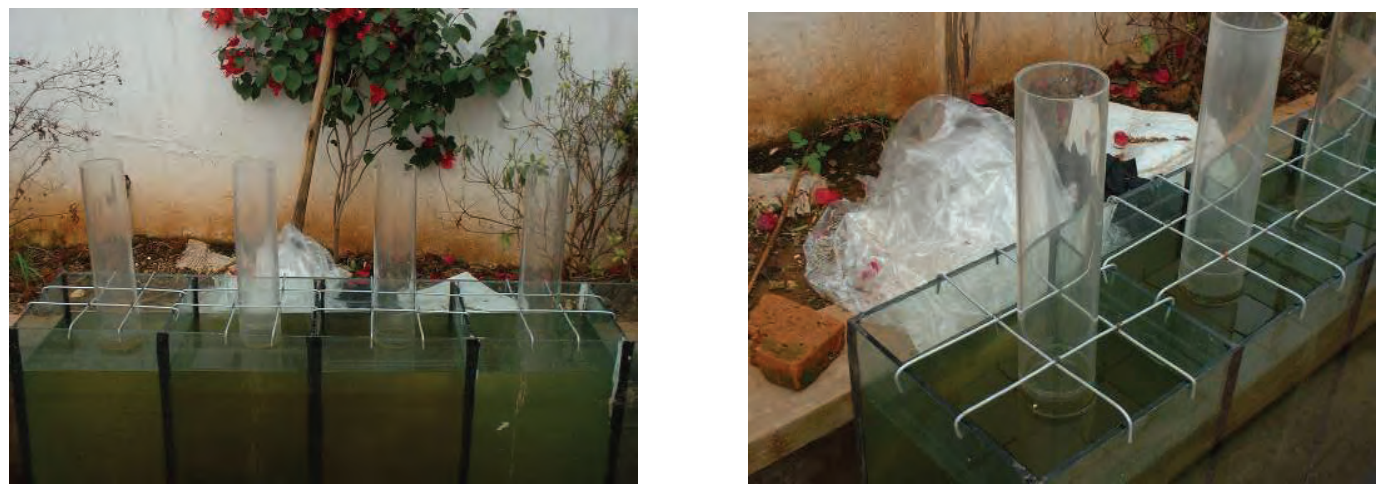

图 2 模拟实验装置图

Fig.2 Patterns of simulation device

仅打开装置正上方黑布，确保外界光源只从水面上方透射进人，同时将 4 支有机玻璃管 $(L: 100 \mathrm{~cm}, \Phi: 8 \mathrm{~cm})$ 分别插人各自装置底泥中，每隔5d 收集装置内样品进行定性定量分析.

\section{2 理化指标测定}

水体 $\mathrm{pH}$ 、溶解氧(DO)及水温的数据均在取样时现场测定. $\mathrm{pH}$ 计为 YSI 63, DO 和水温测定使用 YSI 550A(YSI, USA). 营养盐的测定遵从国家环境保护部制定的国家标准方法.

\section{3 藻类生物量及微囊藻复苏率的变化}

取样时, 首先用虹吸管尽量抽干装置内所有水样(以不扰动底部沉积物为目标), 取部分水样进行相 关分析测定, 余下水样经 Whatman GF/C(Whatman, UK)滤膜过滤后, 缓缓引流再放回装置中, 消除上一 周期内复苏藻类的“污染”. 以叶绿素 a(Chl.a)含量表示复苏藻类细胞的生物量, Chl.a 的测定方法参考《湖 泊富营养化调查规范》(第二版 $)^{[20]}$; 同时使用血球计数板对微囊藻细胞进行计数, 微囊藻细胞净复苏率定 义为每天装置内收集到的微囊藻细胞数除以装置的截面积(相当于底泥面积).

\section{2 结果}

\section{1 不同区域沉积物性状参数}

模拟实验各样点所采集底泥理化参数见表 1. 富藻水经镜检后确认优势种为 $M$. aeruginosa, 且优势 度超过 $99 \%$ 。

表 1 模拟实验各样点所采集底泥理化参数

Tab.1 Sediments' physico-chemical parameters of different sampling sites

\begin{tabular}{cccccccccc}
\hline 采样点 & 含水率 & 硝氮 & 氨氮 & 有机质 & 总磷 & 无机磷 & 有机磷 & 铁铝磷 & 钙磷 \\
\hline $1^{\#}$ & $21.09 \%$ & 1.98 & 84.95 & $8.23 \%$ & 442.86 & 280.47 & 162.39 & 113.81 & 148.77 \\
$2^{\#}$ & $22.96 \%$ & 0.11 & 27.30 & $6.05 \%$ & 515.35 & 292.81 & 222.54 & 92.92 & 151.48 \\
$3^{\#}$ & $23.01 \%$ & 6.14 & 445.25 & $15.85 \%$ & 510.23 & 432.90 & 77.33 & 161.58 & 220.31 \\
$4^{\#}$ & $31.07 \%$ & 1.67 & 162.82 & $19.78 \%$ & 359.33 & 292.67 & 66.66 & 63.00 & 190.23 \\
\hline
\end{tabular}

* 除含水率和有机质为质量百分含量外, 其余指标单位都为 $\mathrm{mg} / \mathrm{kg}$ (干重).

\section{2 理化指标变化}

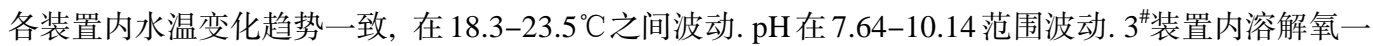
直保持相对较低的水平，除此之外其余装置内波动较大(图 3). 各装置中总氮、总磷的变化总体呈现下降 趋势， 4 个装置中总氮含量分别下降了 $88.7 \% 、 74.7 \%$ 、 $88.6 \%$ 以及 $41.8 \%$; 总磷的含量在实验最后阶段显

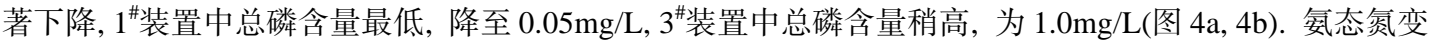




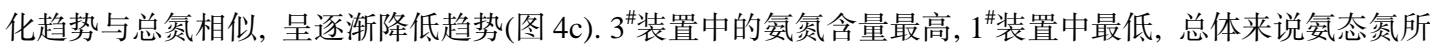
占总氮的比例极低, 不超过 $1 \%$. 硝态氮的变化趋势与氨态氮相反, 实验前 $20 \mathrm{~d}$ 处于上升的状态, 后期迅 速下降, 并且其所占的比例也较低, 不足 10\%(图 4d).
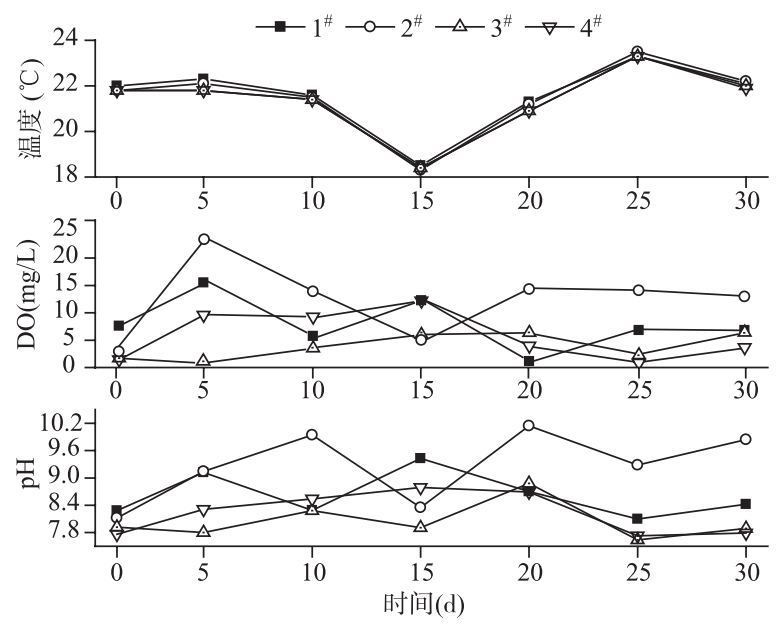

图 3 水温、 $\mathrm{DO}$ 及 $\mathrm{pH}$ 的变化

Fig.3 Variations of water temperature, $\mathrm{DO}$ and $\mathrm{pH}$
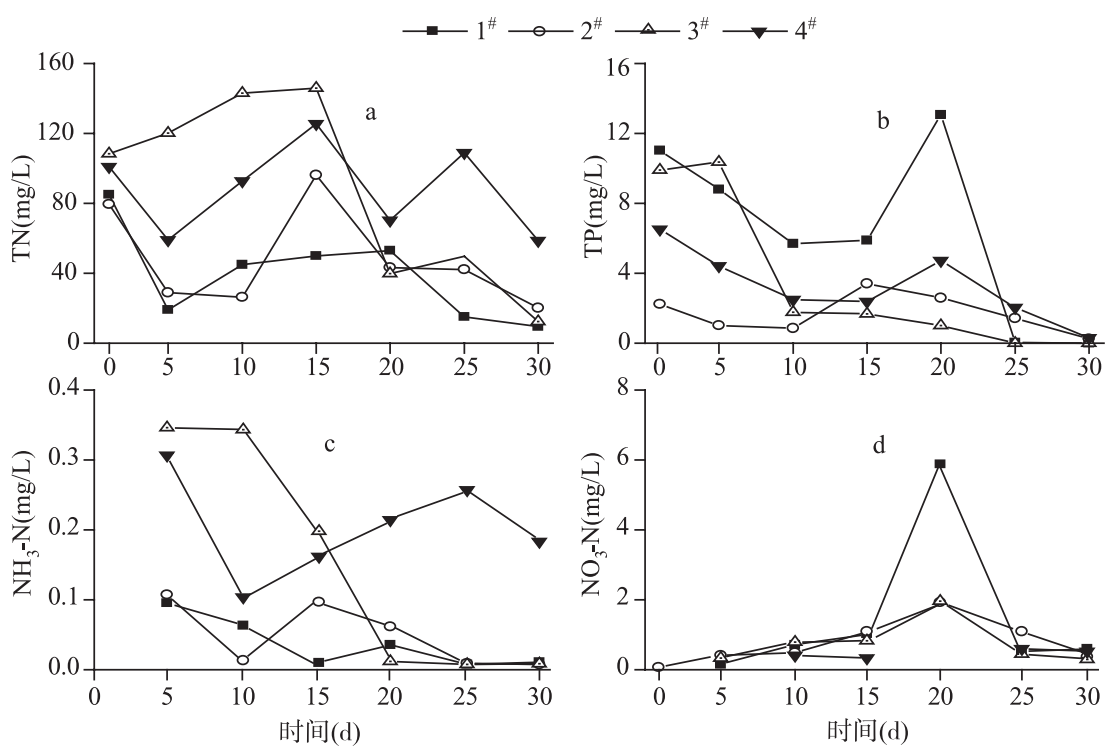

图 4 营养盐浓度变化

Fig.4 Variations of nutrients concentration

\section{3 藻类生物量及微囊藻净复苏率}

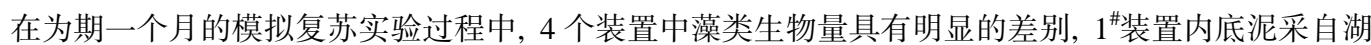

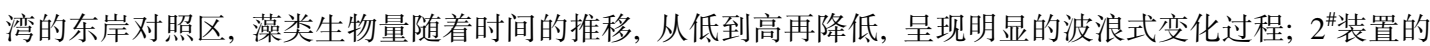
底泥分别采自湖湾吹填区, 藻类生物量在整个实验周期中呈现缓慢上升的趋势, 到实验后期阶段有一个

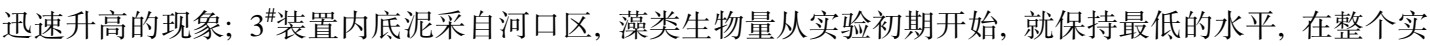
验周期中波动不大； 4 装置中底泥采自西岸对照区，藻类生物量与 $1^{\#}$ 类似，出现先升后降的现象，后期仅 
能检测到少量藻细胞存在(图 5a). $1^{\#}$ 、 $4^{\#}$ 装置内微囊藻细胞数量的变化趋势与藻类总生物量有所不同, 微 囊藻细胞在前期生物量大, 随后显著降低, 而 $2^{\#} 、 3^{\#}$ 装置内微囊藻生物量和藻类总生物量有良好的正相关 性, 变化趋势一致(图 5b). 微囊藻净复苏率在 $0.02 \times 10^{8}-5.76 \times 10^{8} \mathrm{cells} /\left(\mathrm{m}^{2} \cdot \mathrm{d}\right)$ 之间变动, 除 $2^{\#}$ 装置外, 其它 装置均呈现逐步降低的趋势(图 6).
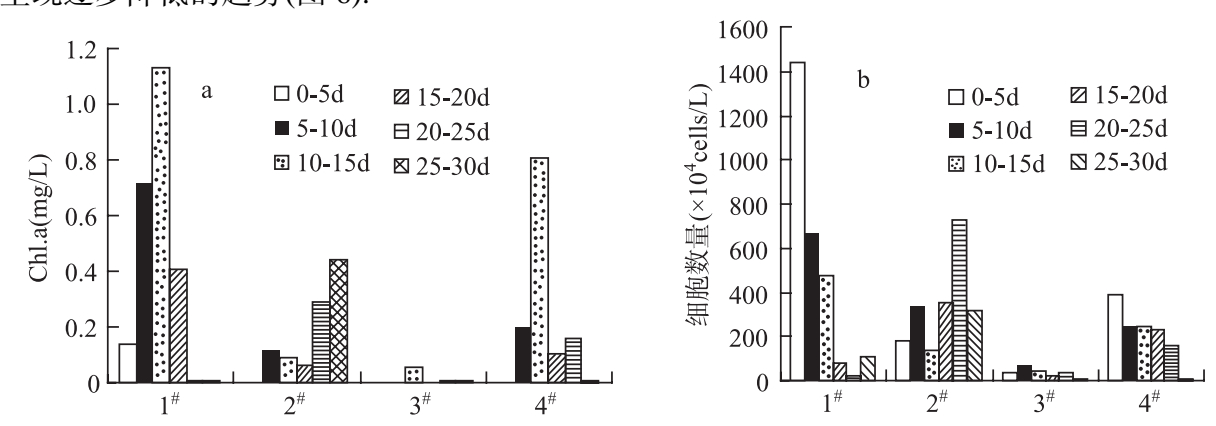

图5 不同时段装置内藻类总生物量(a)和微囊藻细胞数(b)变化

Fig.5 Variations of alga biomass(a) and Microcystis cell numbers(b) in devices in different periods

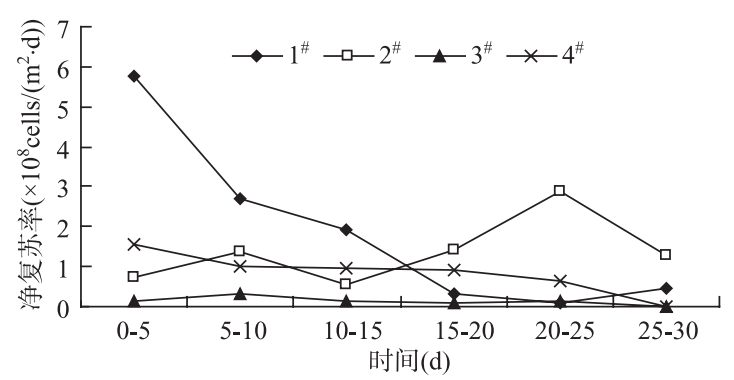

图6 各装置中微囊藻净复苏率变化

Fig.6 Variations of net recruitment rate of Microcystis in devices

\section{3 讨论}

在整个实验周期中 $\mathrm{pH}$ 及水温的变化不大, $\mathrm{pH}$ 呈现碱性，且水温保持在 $18-24^{\circ} \mathrm{C}$ 之间. 前期已有研究 结果显示, 当温度上升到 $15^{\circ} \mathrm{C}$ 时, 微囊藻群体开始复苏进人水体中 ${ }^{[21]}$, 而陶益等以采自太湖底泥中微囊 藻作为研究对象, 发现底泥中微囊藻进人水体的最适温度为 $18-20^{\circ} \mathrm{C}^{[11]}$. 本研究过程中的水温始终保持 在 $18^{\circ} \mathrm{C}$ 以上, 满足微囊藻细胞复苏并进人水柱中生长所需的温度.

由于溶解态氮源不断被藻类复苏生长所利用, 装置中硝酸盐氮及氨氮等含量较低, 但藻细胞对氮元 素的贡献量维持相对稳定, 总氮含量因而相对较高. TN、TP 等营养盐水平虽然呈现逐步下降的趋势, 但 是由于藻类复苏的贡献, 下降趋势较缓慢; 实验周期中, 大量藻类生长对营养盐的消耗, 特别是藻类细 胞被不断移出, 致使营养盐在后期不断降低.

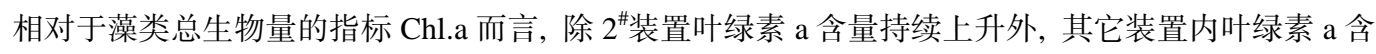
量先上升后下降, 可见在复苏的早期, 藻类显示出了暴发性增殖, 但 3 装置中藻类叶绿素 a 的含量极低, 并且在整个实验周期中始终保持极低的水平, 由此, 我们推测 3 装置中底泥不适合藻类的复苏. 通过进 一步分析比较, 我们发现藻类复苏的生物量与微囊藻生物量的变化趋势不一致, 在 $1^{\#}$ 和 $4^{\#}$ 装置中微囊藻 细胞数在前 $5 \mathrm{~d}$ 基本能达到最大值, 随后逐渐下降, 与此对应的是这两个装置内 TP、TN 的含量也呈现相 同的走势, 可见, 复苏初期的微囊藻能有效利用前期较高水平的营养盐而迅速增殖, 并达到最大生物量; 但随着后期营养盐被消耗, 微囊藻细胞数量不能长时间维持绝对优势, 其它种类如栅藻、小球藻和席藻 等能在微囊藻细胞数量下降后占据优势, 但随着溶解态营养盐的快速消耗, 藻类总生物量在实验后期仍 
不可避免的下降.

2\#装置由于是采自吹填区的底泥，吹填的过程对底泥的扰动能使营养盐的释放加速，同时营养盐释 放在后期呈现回复状态，疏浚和吹填都会破坏原底泥层的营养分布，这一作用能加速底泥中营养物质的 均一化, 且极有可能导致其后期底泥中营养盐释放率增大 ${ }^{[22]}$. 这一营养盐释放动力学特性, 致使其装置 内藻类处于一种连续培养的状态, 并在实验后期显示出生物量逐步升高的特点, 藻类生长有明显的持续 性效应, 并且微囊藻细胞数也在后期保持较高水平, 远多于其它装置.

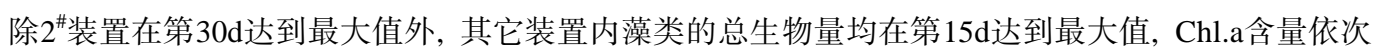
为 $1^{\#}>4^{\#}>2^{\#}>3^{\#}$, 即东岸对照区 $>$ 西岸对照区 $>$ 吹填区 $>$ 河口区, 河口区底泥中藻类Chl.a最大值与其它各位 点相比, 分别占到东岸对照区的 $4.7 \%$, 吹填区的 $11.9 \%$ 及西岸对照区的 $6.6 \%$; 而微囊藻最大生物量及出 现时间上也表现出类似特点，两个对照区均在第5 $\mathrm{d}$ 样品中观察到大量的微囊藻细胞, 河口区底泥中复苏 的微囊藻细胞也在第10d达到峰值, 但是其绝对生物量远低于其它各位点, 占东岸对照区、吹填区及西岸

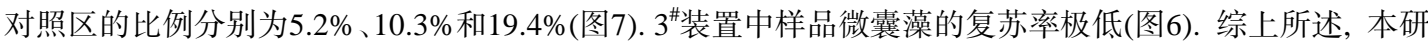
究结果证实了福保湾河口区沉积物环境严重抑制了微囊藻的复苏和生长, 应该不会成为来年这一区域水 华暴发的“种源”.
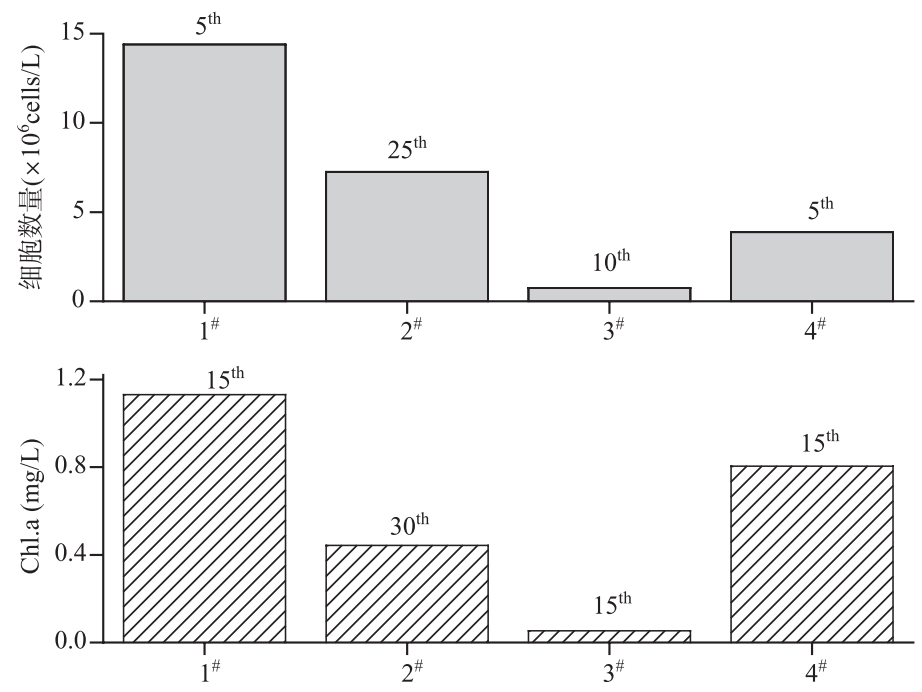

图7 微囊藻细胞数和藻类总生物量最大值及其时间分布

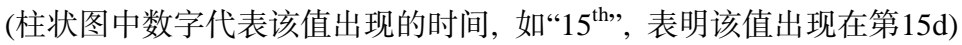

Fig.7 Maximal Microcystis cell number and alga biomass and temporal distribution

微囊藻复苏的区域差异性在滇池福保湾也表现得极为明显, 河口区底泥中微囊藻复苏率远低于吹填 区和对照区. 我们比较了各位点所采集的底泥的理化参数, 河口区底泥中溶解态无机氮(DIN)的含量远远 高于其它各位点，且总磷和有机质的含量也较高，可见其严重受到大清河以及海河的人湖河道的污染影 响, 沉积物中沉降了大量的氮磷营养和有机质, 李宝等的研究表明, 滇池福保湾沉积物中 $\mathrm{NH}_{3}-\mathrm{N}^{-}$和 $\mathrm{PO}_{3}-\mathrm{P}$ 的静态释放速率约为 $2.85-81.96 \mathrm{mg} /\left(\mathrm{m}^{2} \cdot \mathrm{d}\right)$ 和 $0.118-0.265 \mathrm{mg} /\left(\mathrm{m}^{2} \cdot \mathrm{d}\right)^{[23]}$. 从氨态氮和硝态氮的浓度来看, 底 泥中反硝化作用突出, 有研究表明, 硝态氮能被异化还原成氨态氮, 从而防止氮元素从沉积物中流失 ${ }^{[24]}$.

前人的调查研究表明, 滇池藻类生物量与 COD呈现明显的正相关, 其Pearson相关系数达到 $0.929(P<0.01)^{[25]}$, 可见滇池的有机污染状况得以加剧. 而福保湾是滇池北部有机污染最为严重的湖湾, 水体常年发黑发臭, 刺鼻难闻, 溶解氧水平趋近于零. 藻类无法生长, 叶绿素 $\mathrm{a}$ 含量与全湖其它水域相比, 始终保持较低水平(数据未发表). 而我们现在的研究结果也进一步阐明, 福保湾河口区乃至整个湖湾有 机污染严重, 微囊藻在沉降至底泥后, 复苏率远远低于其它区域, 福保湾水华期间微囊藻生物量主要应 
该来源于湾外其它湖区的微囊藻水平迁移，而不是该湖湾内复苏的微囊藻自身繁殖的垂直迁移. 本实验的研究结果从全新的角度阐释了滇池福保湾尽管富营养化程度极高但藻类生物量不高的原因. 同时对今后滇池乃至其他地区蓝藻水华污染防治技术与管理措施提供了新的思路.

\section{4 参考文献}

[1] 万 能. 滇池微囊藻越冬及复苏的生态生理学研究[博士学位论文]. 武汉: 中国科学院水生生物研究所, 2008.

[2] Barbiero RP, Welch EB. Contribution of benthic blue-green algal recruitment to lake populations and phosphorus translocation. Freshw Biol, 1992, 27(2): 249-260.

[3] Forsell L, Pettersson K. On the seasonal migration of the cyanobacterium Gloeotrichia echinulata in Lake Erken, Sweden, and its influence on the pelagic population. Mar Freshw Res, 1995, 46(1): 287-293.

[4] Perakis SS, Welch EB, Jacoby JM. Sediment-to-water blue-green algal recruitment in response to alum and environmental factors. Hydrobiologia, 1996, 318(3): 165-177.

[5] Fryxell GA. Survival strategies of the algae. London: Cambridge University Press, 1983.

[6] Huber AL. Factors affecting the germination of akinetes of Nodularia spumigena (Cyanobacteriaceae). App Environ Microbiol, 1985, 49(1): 73-78.

[7] Hansson LA. Factors initiating algal life-form shift from sediment to water. Oecologia, 1993, 94: 286-294.

[8] van Dok W, Hart BT. Akinete germination in Anabaena circinalis (Cyanophyta). J Phycol, 1997, 33(1): 12-17.

[9] Rengefors K, Karlsson I, Hansson LA. Algal cyst dormancy-a temporal escape from herbivory. Proc Roy Soc Lond, 1998, 265: 1353-1358.

[10] 李阔宇, 宋立荣, 万 能. 底泥中微囊藻复苏和生长特性的研究. 水生生物学报, 2004, 28(2): 113-118

[11] 陶 益, 孔繁翔，曹焕生等. 太湖底泥水华蓝藻复苏的模拟. 湖泊科学, 2005, 17(3): 231-236.

[12] Jónasson PM. Ecology and production of the profundal benthos in relation to phytoplankton in Lake Esrom. Oikos, 1972, 14(Suppl): 1-148.

[13] Marcus NH, Schmidt-Gengenbach J. Recruitment of individuals into the plankton: The importance of bioturbation. Limnol Oceanogr, 1986, 31(1): 206-210.

[14] Fukuhara H. The effect of tubificids and chironomids on particle redistribution of lake sediment. Ecol Res, 1987, 2: 255-264.

[15] Kearns CM, Hairston NGJ, Kesler DH. Particle transport by benthic invertebrates: Its role in egg bank dynamics. Hydrobiologia, 1996, 332(1): 63-70.

[16] Ståhl-Delbanco A, Hansson LA. Effects of bioturbation on recruitment of algal cells from the "seed bank" of lake sediments. Limnol Oceanogr, 2002, 47(6): 1836-1843.

[17] Yin CT, Li WZ, Du Y et al. Identification of a gene, ccr-1(sll1242), required for chill-light tolerance and growth at $15^{\circ} \mathrm{C}$ in Synechocystis sp. PCC 6803. Microbiol, 2007, 153: 1261-1267.

[18] Yang Y, Yin CT, Li WZ et al. $\alpha$-tocopherol is essential for the acquired chill-light tolerance (ACLT) in the cyanobacterium Synechocystis sp. PCC 6803. J Bacteriol, 2008, 190: 1554-1560.

[19] Wan N, Tang J, Li QM et al. The responses of Microcystis to sediment environments and the assessment for its overwintering-a simulation study in a novel device. Fresen Environ Bull, 2008, 17(12b): 2146-2151.

[20] 金相灿，屠清瑛主编. 湖泊富营养化调查规范(第二版). 北京：中国环境科学出版社, 1990.

[21] Reynolds CS. Growth and buoyancy of Microcystis aeruginosa Kütz. emend. Elenkin in a shallow eutrophic lake. Proc Roy Soc Lond B, 1973, 184: 29-50.

[22] 范成新, 张＼cjkstart路, 王建军等. 湖泊底泥疏浚对内源释放影响的过程与机理. 科学通报, 2004, 49(15): 1523-1528.

[23] 李 宝, 丁土明, 范成新等. 滇池福保湾底泥内源氮磷营养盐释放通量估算. 环境科学, 2008, 29(1): 114-120.

[24] Axler RP, Reuter JE. Nitrate uptake by phytoplankton and periphyton: whole-lake enrichments and mesocosm- ${ }^{15} \mathrm{~N}$ experiments in an oligotrophic lake. Limnol Oceanogr, 1996, 41(4): 659-671.

[25] 万 能, 宋立荣, 王若南等. 滇池藻类生物量时空分布及其影响因子. 水生生物学报, 2008, 32(2): 184-188. 